\title{
A flexible microprocessor system for the measurement of cell size
}

\author{
JOAN M ROUND, DA JONES, RHT EDWARDS \\ From the Department of Human Metabolism, Faculty of Clinical Sciences, University College London, \\ The Rayne Institute, University Street, London WC1 6JJ
}

SUMMARY A flexible system for the measurement of length and area is described. The system consists of the Reichert Jung MOP-1 area measuring device interfaced with a Commodore PET computer. Its use is illustrated by the planimetric measurement of cross sectional areas in histochemical preparations of normal and diseased muscle. While measurements are being made data can be displayed on the computer screen either in numerical form or as a frequency histogram together with simple statistical analyses. Hard copy can be obtained from an attached printer. Mean values for fibre area in normal human skeletal muscle are reported.

An alternative, widely used method of calculating fibre area from the lesser diameter was found to give a consistent underestimate of approximately $30 \%$ when compared with our planimetric method. In diseased muscle with abnormally shaped fibres the discrepancy is even larger; such fibres can be identified using a "form factor" which relates the area of a cell to its perimeter. This rapid, accurate and flexible system is also suitable for the measurement of many different types of graphical record.

Numerous methods have been used to estimate the size of muscle fibres in transverse section. ${ }^{1-4}$ Some methods, such as planimetry are accurate but timeconsuming. Others-for example, measuring the lesser or greater fibre diameters are quicker but considerably less accurate and if used to calculate area lead to further errors as the cross section of a muscle fibre is rarely circular. The accurate measurement of fibre cross sectional area is important as it is directly related to muscle strength and in wasting diseases a selective atrophy of one fibre type may occur.

It is generally accepted that planimetry, if available provides the most accurate method of measuring areas $^{5}$ and with the development of microprocessors coupled to digitising tablets the ease with which planimetry can be performed is greatly increased. We have evaluated a convenient and rapid system which couples an area measuring device (ReichertJung MOP-1) with a bench top microcomputer (Commodore PET). A brief report of this system (MOPPET) has been published. ${ }^{6}$

\section{Material and methods}

NEEDLE BIOPSY AND HISTOCHEMISTRY Samples of human muscle, usually from the quad-

Accepted for publication 20 October 1981 riceps, are obtained by the needle biopsy technique. ${ }^{\text {? }}$ The muscle samples are orientated under a dissecting microscope to give parallel fibre bundles and these are kept vertical on cork discs using OCT compound mounting medium (Lab Tek products, Miles Labs Inc, Illinois, USA). The specimen is frozen rapidly in isopentane which has been cooled to its freezing point in liquid nitrogen. The blocks are stored at $-60^{\circ} \mathrm{C}$. We do not stretch the specimens before freezing and electron micrographs taken at the same time have consistently shown the sarcomeres to be fully contracted. For area measurements cryostat sections are cut at $8 \mu \mathrm{m}$ and stained for myosin ATPase activity at $\mathrm{pH} 9 \cdot 4 .{ }^{8}$

\section{MICROSCOPY}

Sections are examined using a binocular microscope with drawing tube attachment which permits the image of the MOP drawing tablet and the image of the specimen to be superimposed in the same plane.

The microscope and side arm are calibrated using a Vernier slide with $\mathrm{a} \times 25$ objective and $\times 10$ eyepieces. The side arm is adjusted so that $0.1 \mathrm{~mm}$ on the Vernier slide is equivalent to $20 \mathrm{~mm}$ on the tablet. The magnification factor $(\times 200)$ is stored in the MOP microprocessor and used to give a readout of true area (in $\mu \mathrm{m}^{2}$ ). This magnification gives a conveniently sized image for drawing, with normal 
muscle a single field usually contains about $25-30$ fibres.

\section{AREA MEASUREMENTS}

The fibres are outlined using the drawing pen. The passage of the pen over the tablet produces a stream of co-ordinates from which the MOP microprocessor calculates both the perimeter and area of each cell drawn. The measurements of length and area can then be directly printed out or passed through a serial interface (RS 232) to the PET computer (Fig. 1). Algorithms have been written to receive, display and store data. Machine code subroutines present on a programmable ROM (PROM) are used for the data transfer, displaying of stored data as a histogram, automatic scaling of the histogram and for printing out the contents of the PET screen to an attached printer. Data on area and perimeter for three different cell types can be simultaneously stored and up to 250 measurements made on each cell type. As the measurements are being made the data may be displayed as either a listing or a histogram together with a running mean and standard deviation. The histogram usually consists of 20 bars and the bin size can be determined by selecting the size of the largest bin. Any values greater than this are placed in the highest bar. An additional feature relates the area of the structure to its perimeter giving a "form factor" (FF). The FF indicates the shape of the cell by comparing the perimeter of the fibre with the perimeter of a circle of the same area, so that:

$$
\mathrm{FF}=\frac{4 \pi \mathrm{A}}{\mathrm{P}^{2}}(\mathrm{~A}=\text { area } \mathrm{P}=\text { perimeter of the cell })
$$

If the cell is circular the FF will be $1 \cdot 0$, any deviation from the circular gives a smaller value. Most normal muscle cells cut in true cross section give an FF of 0.8 with a range of 0.85 to 0.75 . Examples of different cell shapes and their appropriate FF are shown in Fig. 2.

All original data can be stored on a disk for future recall and analysis.

\section{Results}

ACCURACY AND PRECISION

Drawing around an area of exactly $200 \mathrm{~mm}^{2}$ (on graph paper) 20 times gave a result which was

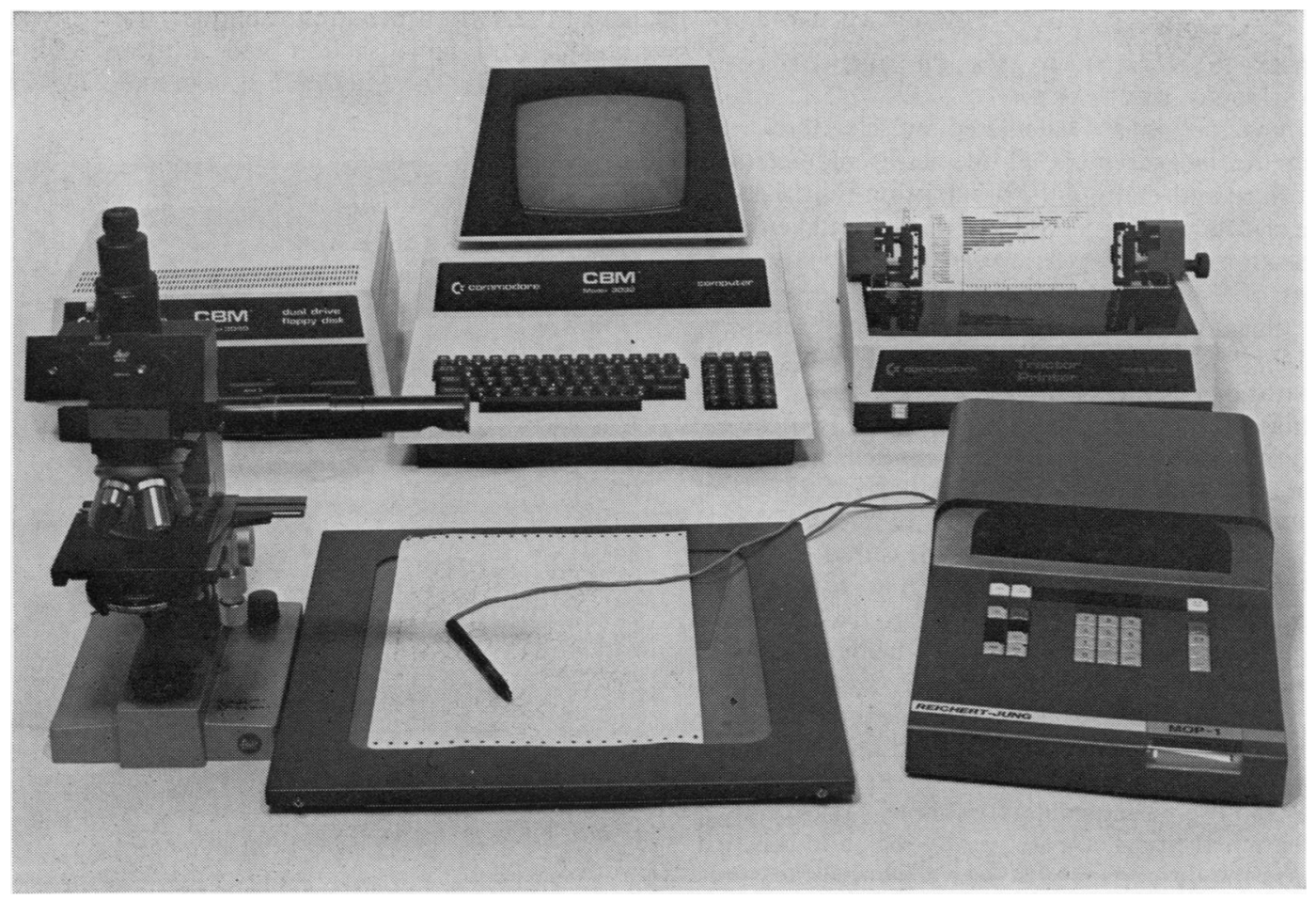

Fig. 1 Microscope and microprocessor system for measuring cell areas. Front, left to right, microscope with drawing tube side arm, MOP drawing tablet, MOP microprocessor. Back row left to right, disk storage unit, PET computer, printer. 


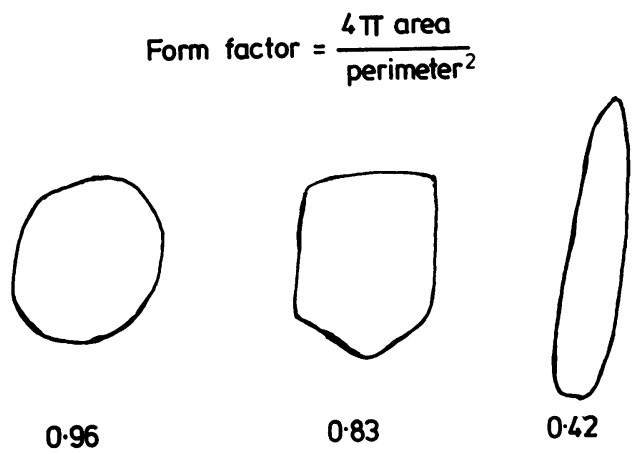

Fig. 2 Form factor $(F F)$ relating cell perimeter to area. Three examples of cell shape are shown with their FF. Note that a circle would have an FF of 1.0.

accurate to $0.5 \%$; the coefficient of variation for this was $1.7 \%$.

One preparation of quadriceps muscle taken from a normal male volunteer was used to evaluate the error by one operator when counting one cell 100 times. The coefficient of variation for this task was $1.9 \%$ for a mean cell area of $6900 \mu \mathrm{m}^{2}$. There was little "interoperator" variation in performance.

\section{COMPARISON WITH DIAMETER METHOD OF \\ MEASURING CELL AREA}

We have previously calculated muscle fibre areas using the measurement of the lesser diameters of each fibre and making the assumption that the cells were circular. This method has the advantage that if the section is not fully transverse a falsely large area is not obtained. ${ }^{4}$ More recently it has been shown that unless the section is very far from transverse $\left(>15^{\circ}\right)$ the error involved is small. ${ }^{5}$ If muscle preparations are carefully orientated under a dissecting microscope before freezing this problem seldom arises. Non-transversely cut cells are identifiable to the trained observer and their measurement can usually be avoided. A number of normal muscle fibre preparations have been measured by both methods (Fig. 3) and it is clear that a systematic underestimate occurs when using diameters to calculate area. Areas calculated from the lesser diameters give an answer which is approximately $70 \%$ of the true area. The extent of the underestimate is clearly related to the fact that most normal muscle fibres have an FF form factor of around 0.8. In diseased muscle abnormal fibre shapes-for example, small angular fibres, are frequently seen and this will increase the discrepancy between true area measurements and areas estimated from measurements of the lesser diameter. In a biopsy from a patient with a severe endocrine myopathy (see Fig. 4), the mean

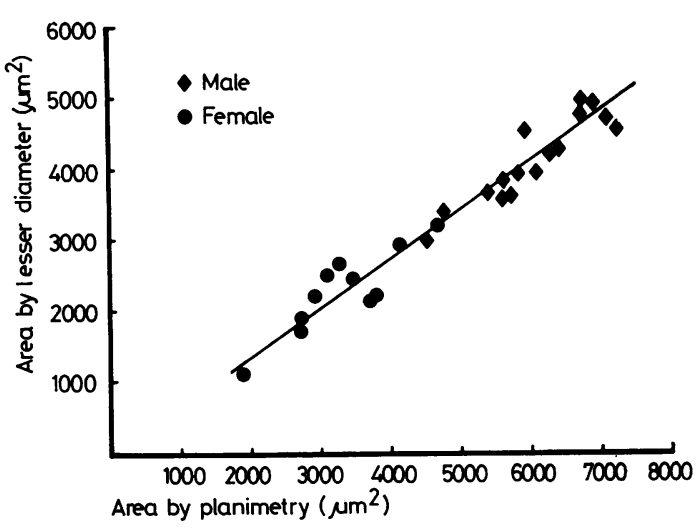

Fig. 3 Comparison between muscle fibre areas measured by lesser diameter (ordinate) and by MOP planimetery (abscissa). A systematic underestimate occurs when calculating area from lesser diameter giving an answer for normal subjects approximately $70 \%$ of the true value.

type II fibre area, obtained using the MOPPET system was $326 \mu \mathrm{m}^{2}$ as compared to a value of $82 \mu \mathrm{m}^{2}$ obtained by measuring the lesser diameter. The FF for these cells was $0 \cdot 47$. This finding was not due to the section being cut obliquely as the type I fibres in the same section had a mean area of $2692 \mu \mathrm{m}^{2}$ using the MOPPET system and $2226 \mu \mathrm{m}^{2}$

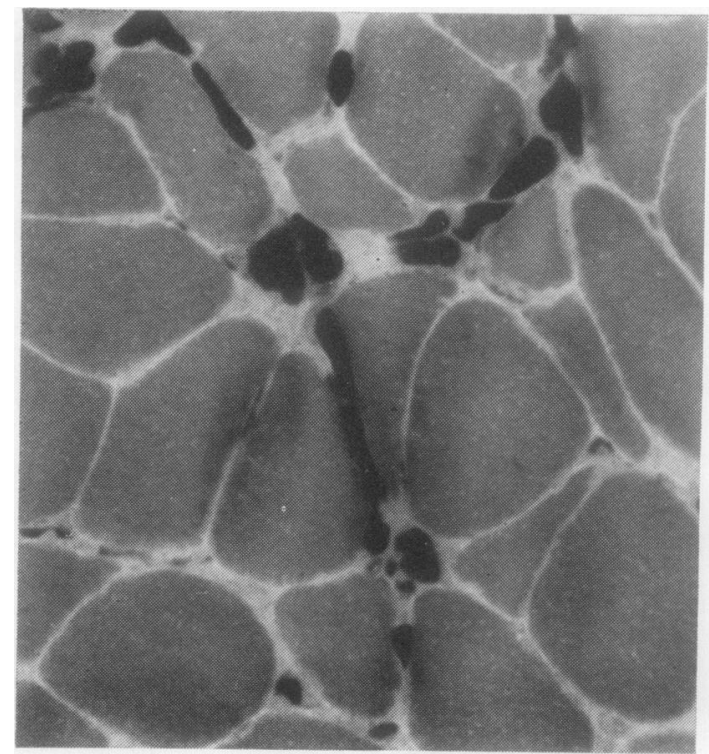

Fig. 4 Transverse section of muscle biopsy from a patient with severe endocrine myopathy. Form factor for type I (light) fibres $0 \cdot 85$, the mean FF for type II (dark) fibres 0.47 . 


\section{SPECIMEN DYST/SOL/T'YFE 1 AREA/FFEQUENC'Y SPECIMEN D'T'S/SOL/TYPE 2 ARER/FREQUENCY}
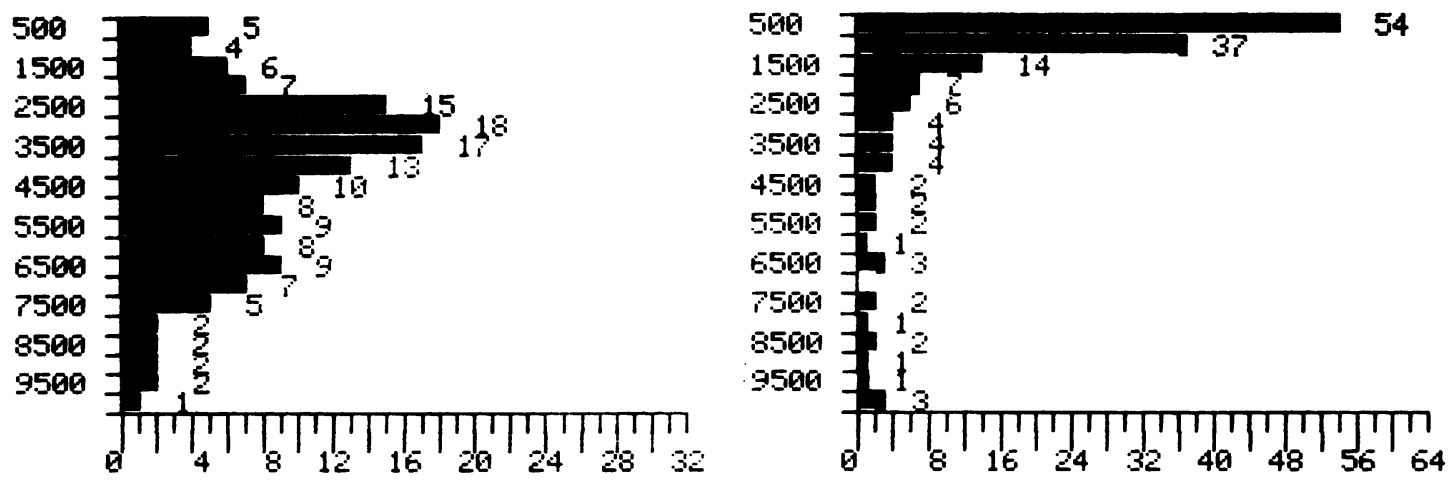

Fig. 5 Histograms of fibre area of soleus muscle from a patient with muscular dystrophy. The distribution of the type II fibres shows marked skew. Vertical axis, fibre area in $\mu^{2}$; horizontal axis, number of fibres.

by the lesser diameter method. The FF for the type I fibres was $0 \cdot 85$.

In diseased muscle where the distribution of fibres is not Gaussian, simple statistics can be inappropriate and misleading. In these circumstances it is particularly valuable to see the histogram of fibre size distribution. Histograms for a sample of dystrophic soleus muscle are shown in Fig. 5. The distribution of the type I fibres is normal while that for the type II fibres is heavily skewed. In diseased muscle such as this more can be learned from a histogram of the areas than by manipulation of the data into a form from which means and standard deviations can be calculated.

Using the MOPPET system a single muscle biopsy can be quantified in about 10 minutes, measuring about 100-150 cells of each fibre type. This time includes plotting histograms, calculating statistics and FF and storing the data on disk. Similar measurements made by hand would take at least an hour. In our laboratory the mean range for fibre areas for men was from $3500-7500 \mu \mathrm{m}^{2}(\mathrm{n}=26)$ and for women $2000-4500 \mu \mathrm{m}^{2}(\mathrm{n}=18)$. These values were from subjects of average build and within the 10th-90th centile for height and agree well with previously reported areas measured by planimetry. ${ }^{910}$ It was apparent that fibre area is related to stature and this may account for the differences between the men and women. No significant differences were seen in the mean areas of the type I or II fibres in the normal subjects nor was there any significant difference between the preparations stained with haematoxylin and eosin or for ATPase.

The methods described have the advantage of speed, together with a high degree of operator control and flexibility. The operator has full control of the fields measured and can reject damaged or obliquely cut cells as well as artifacts and other structures such as blood vessels and connective tissue. The data can be displayed in a number of different ways to suit the particular comparisons being made and can be stored and recalled at a later date.

The system is not dedicated to one task. The MOP can be used to send co-ordinates to the PET and programmes have been written which use these to quantify lung flow volume loops plotted on an $\mathrm{XY}$ recorder in a respiratory function laboratory, ultrasound records of aortic blood flow, the density of particles on freeze fracture faces of cell membranes and the distribution of bone erosions seen on $x$-ray of the hand. In addition the microcomputer is available as a general laboratory instrument for interfacing with other instruments, for data and reference storage and for word processing.

\section{References}

${ }^{1}$ Sissons HA. Further investigations of muscle fibre size. Research Committee of the Muscular Dystrophy Group of Great Britain, eds. In: Proceedings of the 3rd Symposium on Research in muscular dystrophy. London, Pitman Medical, 1965:107.

2 Adams RD, Coers C, Walton JN. Report of a subcommittee on the quantitation of muscle biopsy findings. J Neurol Sci 1968;6:179-88.

${ }^{3}$ Edstrom L, Nystrom B. Histochemical types and fibres in normal human muscles. An autopsy study. Acta Neurol Scand $1969 ; 45: 257-69$.

4 Dubowitz V, Brooke MH. Muscle biopsy: a modern approach. London: WB Saunders \& Co, 1973:74.

5 Clancy MJ, Herlihy PD. Assessment of changes in myofibre size in muscle. In: de Brer $\mathrm{H}$, Martin J, eds. EEC 
Seminar on patterns of growth and development in cattle, Ghent 1977. The Hague, Martinas Nyhoff, 1978:203-18.

${ }^{6}$ Jones D, King MF, Round JM. Moppet: a rapid and accurate system for the measurement of muscle fibre cross sectional areas. J Physiol 1980;305:5p-6p.

${ }^{7}$ Edwards RHT, Young A, Wiles CM. Needle biopsy of skeletal muscle in the diagnosis of muscle function and repair. $N$ Engl J Med 1980;302:261-71.

${ }^{8}$ Round JM, Matthews Y, Jones DA. A quick simple and reliable method for ATPase in human muscle preparations. Histochem $J$ 1980;12:707-10.

${ }^{9}$ Costill DL, Coyle EF, Fink WF, Lesmes GR, Witzmann
FA. Adaptations in skeletal muscle following strength training. J Appl Physiol 1979;46:95-106.

${ }^{10}$ Gollnick PD, Armstrong RB, Saltin B, Saubertiv CW, Sembrowich WL, Sheperd RE. The effect of training on enzyme activity and fibre composition of human skeletal muscle. J Appl Physiol 1973;34:107-11.

Requests for reprints to: Dr JM Round, Department of Human Metabolism, Faculty of Clinical Sciences, University College London, The Rayne Institute, University Street, London WC1 6JJ, England.

\section{Reports and Bulletins prepared by the Association of Clinical Biochemists}

The following reports and bulletins are published by the Association of Clinical Biochemists. They may be obtained from The Publishing Department, British Medical Journal (ACB Technical Bulletins), BMA House, Tavistock Square, London WC1H 9JR. Overseas readers should remit by British Postal or Money Order.

SCIENTIFIC REVIEWS (price $£ 1 \cdot 00 / \$ 2.00$ each)

1 The assessment of thyroid function March 1971 FV FLYNN and JR HOBBS

2 Renal function tests suitable for clinical practice January 1972 FL MITCHELL, N VEALL, and RWE WATTS

3 Biochemical tests for the assessment of fetoplacental function May 1975 CE WILDE and RE OAKEY

4 Test of exocrine pancreatic function March 1977 AH GOWENLOCK

5 Assay of cholinesterase in clinical chemistry March 1979 ELSIE SILK, J KING, and MARY WHITTAKER

TECHNICAL BULLETINS (price $£ 1 \cdot 00 / \$ 2.00$ each)

22 Bilirubin standards and the determination of bilirubin by manual and technicon AutoAnalyzer methods January 1971 BARBARA BILLING, RUTH HASLAM, and N WALD

23 Interchangeable cells for spectrophotometers and fluorimeters September 1971 ss BROWN and AH GOWENLOCX

24 Simple tests to detect poisons March 1972 BW MEADE et al.

25 Blood gas analysers May 1972 K DIXoN

26 Kits for enzyme activity determination September 1972 SB ROSALKJ and D TARLOW

27 Assessment of pumps suitable for incorporation into existing continuous flow analytical systems November 1972 A FLECK et al.

28 Routine clinical measurements of transferrin in human serum September 1973 K DIXON
29 Control materials for clinical biochemistry (5th edition) September 1973 JF STEVENS

30 Notes on the quality of performance of serum cholesterol assays September 1973 sS BROWN

31 Determination of uric acid in blood and in urine July 1974 RWE WATTS

32 A survey of amino acid analysers readily available in the United Kingdom September 1974 JE CARLYLE and $P$ PURKISS

33 Definitions of some words and terms used in automated analysis November 1974 A FLECK, R ROBINSON, SS BROWN, and JR HOBBS

34 Measurement of albumin in the sera of patients January 1975 LINDA SLATER, PM CARTER, and JR HOBBS 35 Investigation of the validity of temperature correction factors for serum aspartate and alanine transaminases March 1975 SB ROSALKI et al.

36 Factors influencing the assay of creatinine November 1975 JGH COOK

37 A survey of enzyme reaction rate analysers readily available in the United Kingdom July 1977 RA SAUNDERS and RF BURNS

38 Transport of specimens for clinical chemistry analysis November 1977 P WILDING, JF ZILVA, and CE WILDE

39 A scheme for the evaluation of diagnostic kits May 1978 PH LLOYD

40 A practical guide to gamma-counting in radioimmunoassay January 1980 CE WILDE and D OTTEWELL 41 The use of biochemical tests in the diagnosis ef disorders of calcium metabolism July 1980 ANGELA FAIRNEY 